\title{
REFLECTION
}

\section{Disenfranchised Grief and Physician Burnout}

\author{
Deborab Latbrop, MD, MAT \\ Independent Physicians, SC, Madison, \\ Wisconsin
}

\begin{abstract}
Over the span of their career, physicians experience changes to their professional role and professional identity. The process of continual adaptation in their work setting incurs losses. These losses can be ambiguous, cumulative, and may require grieving. Grief in the workplace is unsanctioned, and may contribute to physicians' experience of burnout (emotional exhaustion, depersonalization, low sense of achievement). Acknowledging loss, validating grief, and being prescient in dealing with physician burnout is essential.
\end{abstract}

Ann Fam Med 2017;15:375-378. https://doi.org/10.1370/afm.2074.

would like to propose that we have a grieving physician workforce. Physicians have traditionally encountered losses-regularly confronting death in the context of the care of their patients. They may not, however, recognize that they are surrounded by more ambiguous losses, including rapidly changing expectations of their duties, roles, and regard.

Any transition offers the potential for loss, and losses incur grief. ${ }^{1(\mathrm{p} 3)}$ Kennth Doka defines disenfranchised grief as "grief that persons experience when they incur a loss that is not or cannot be openly acknowledged, publicly mourned, or socially supported."1(p4) Disenfranchised grief may contribute to the development and persistence of physician burnout. To adequately address the current crisis of physician burnout, the underrecognized role of grief in the physician experience must be addressed.

\section{Role of Workplace Transitions in Loss}

Physicians' work responsibilities have undergone significant changes in the last two decades. These include:

- The trend from running a private practice to becoming employees (changes in authority, level of autonomy, role, responsibilities)

- Implementation of electronic health records

- Trend toward team-based vs physician-visit-based care and the rise of a midlevel practitioner presence

- Insurance product refinement (pre-authorizations, panel size changes)

- Increasing regulatory and administrative aspects

- Evolving credentialing requirements

These changes, while incremental, have been continuous, and taken en masse, have required adjustments in how we practice medicine. These adaptations incur loss. For example, bringing computers into the patient room, while offering certain efficiencies, changes the initial moments of the patient-physician interaction: a login experience now accompanies the personal salutation. We have lost the initial, unadulterated moment between physician and patient/family. Similar small transitions over several decades have an additive effect, and the impact on physicians' work experience is significant.

Adapting to such workplace transitions contributes to stress, ${ }^{2}$ and loss. Louis Trudel, et al, note that if a worker's integrity is undermined by the work experience there is a "mourning of the loss of a part of oneself 
engaged in work." ${ }^{\prime \prime}$ An example might be a physician whose sense of professional integrity feels threatened by his or her perceived inability to deliver care at an acceptable pace for the care to seem adequate, effective, or fruitful. ${ }^{4}$ Such situations can arise when scheduling is dictated by central templates, relative value unit (RVU) capture, contractual or marketing-based panel sizes, rather than by patient or physician needs. This can invoke loss and mourning.

Further, physicians who experience burnout experience the loss of their own ability to engage energetically, enthusiastically, or effectively in the workplace. Currently, occupational burnout (defined as exhaustion, detachment/cynicism, low sense of achievement ${ }^{5}$ ) is present in $37 \%$ to $53 \%$ of physicians. ${ }^{6}$ Drs Christine Maslach and Michael Leiter, pioneers in the field of occupational burnout, maintain that managementdriven elements of work life are responsible for occupational burnout. ${ }^{7}$ Workload, reward, control, community (team climate/trust), values, and fairness are key spheres in which organizational processes create a setting which promotes either engagement, or burnout. To illustrate, if a doctor leaves a partnership practice for an employed setting and experiences an increased administrative workload, ${ }^{8}$ yet as an employee has less say in the matter, the setting may engender an increased risk for burnout (workload, control, and reward are affected). For physicians with burnout, the loss of engagement at work is a loss of a part of themselves.

\section{Physician's Experience of Loss}

The role of organizational, as well as structural (regulatory, fiscal, legal), factors in physicians' changing work environment cannot be minimized. But it is the physician's experience, after all, that is affected. While other professional and industrial sectors have faced upheavals, physicians face a long lead time between entering medical school and being able to work independently. Dissonance may develop between the expected role and regard a physician held before entering the profession, vs one's current experience. This may strike the doctor directly during patient care, or by extrapolation, from institutional, governmental, or societal cues. For example, there is a role adjustment required for physicians to go from being the holder of unique knowledge, to that of an expert partner aiding patients through Internet-mediated doctoring.

Cultural shifts in our changing medical landscape also play out semantically: the term "provider" now denotes physicians and any number of other health care professionals. Doctors are thus identified by the service they provide, rather than by the professional title which embodies hard-sought training, ethical mandates, and knowledge-based authority. In these ways physicians receive conflicting and/or marginalizing messages, which results in a loss of occupational esteem, and can evoke internal dissonance.

\section{Disenfranchised Grief}

When workplace transitions affect pivotal aspects of the physician's professional identity, adaption may engender significant loss. "Where there is loss, there is grief," and for those lamenting, even on an inexplicit level, grieving drains one's physical energy, emotional stamina, and at times, intellectual capability. ${ }^{9(p 94)}$ Grieving, therefore, both at work and because of work, could contribute to what we typically define as risk factors for professional burnout. To date, physician burnout has been addressed primarily with informal strategies of stress reduction, lifestyle coaching, and trying to build physician resilience. Yet this approach erroneously implies too little resilience or a weakness within the physician, while diminishing or even exonerating the health care delivery apparatus and organizations in which physicians work. In so doing, the physicians' grief, and suffering, is disenfranchised by the system.

The 1989 compilation work entitled Disenfranchised Grief: Recognizing Hidden Sorrow addresses the conflict between the needs of the individual experiencing loss, and the goals of the workplace. At work, "Emotions and feelings are discounted, discouraged and disallowed," and therefore all losses are disenfranchised in the workplace. ${ }^{9\left({ }^{p 92)}\right.}$ Additionally, physician loss is underacknowledged due to limited collegial exchange, the hierarchical nature of the medical milieu, and concerns about career consequences (eg, being labeled as disruptive or a whiner).

Privately, physicians may defensively suppress selfawareness of their grief. Medical training's historic "hidden curriculum" often required of trainees an initial loss of autonomy, sense of mastery, sleep, outside interests, etc, and cultivated the use of such defensive strategies. Mid- and late-career physicians now increasingly hear the skills and nonclinical qualities promoted within that training system deemed obsolete, eroding acknowledgment of developed acumen and bringing to question the personal opportunity costs of their acquisition. Reflecting on the impact of sacrifice can be painful, and evaded through defensive techniques. In this way, physicians may suppress or minimize the recognition of their losses, which further complicates the experience of grieving.

\section{A Systems Issue}

Although physicians are suffering, efforts to assist them can exacerbate the problem. For example, in 
employer-based models, physician extenders are often brought in under the auspices of increasing access and reducing physician burden, but with unexpected results. For example, using nurse practitioners potentially decreases highly valued elements of work such as continuity with established patients, control of patient care plans, and revenue (if high RVU/timeexpenditure visits are siphoned off). Meanwhile, the physician acquires supervisory tasks, for which compensatory adjustment or other rewards (mentoring, scheduling flexibility, etc) may be insufficient. Further, physicians may interpret this as a sign that their extensive training, board certification, and experience are not as valued as their (risk-incurring, supervisory) signature. This again can undermine physician integrity, and sets up the dynamic for loss and grief.

Similarly, organizations' attempts at resiliencetraining to combat workplace burnout can further disenfranchise physicians' experiences. First, evidence in the literature is insufficient to support that stressreduction/mindfulness techniques are effective against physician burnout; studies to date are lacking appropriate controls, power, generalizability and/or statistical significance. ${ }^{10-15}$ Second, evidence points to occupational burnout being a consequence of system processes $^{7}$ whereas promoting resiliency training implies a personal failing on the part of the physician. In fact, physicians have already demonstrated their high resiliency through successful completion of their medical education and training and some argue it is actually the high level of physician resiliency which has allowed system processes to become ripe for occupational burnout! When misconceptions of etiology, locus, or remedy for physician burnout are promoted, physicians' authentic experience is further disenfranchised.

\section{Moving Forward}

Research in business management and industrial psychology has clarified how systems need to attend to knowledge-based workers' work experience to avoid dissatisfaction and burnout. Recently, increased attention has been paid to the effects of organizational climate ${ }_{,}^{4}$ direct supervisor's leadership skills, ${ }_{1}^{16}$ evidence of work progress, ${ }^{17}$ and physician-centered workplace initiatives. ${ }^{18}$ Occupational burnout can be prevented when research informs the solutions. But first, we need to pay attention to the losses that impact physicians. We need to name them, and validate physicians' experiences of transition, adaptation, and loss, and examine how health systems perpetuate losses. ${ }^{1\left(p^{3} 13\right), 19}$

Suffering physicians could benefit when they acknowledge changes in their work environment incur loss, chose to address any pain from hidden grief, withdraw emotional energy from earlier professional expectations, and reframe their professional future..$^{1(\mathrm{p} 191)}$ Meeting this challenge may require accessing resources or addressing personal and/or professional conflicts from which doctors have traditionally shied away. Most of all, as in all grief, physicians will need to accept that their losses are real-and permanent.

For physicians caring for physicians as their patients, it is an opportune moment to name occupational losses as such, validate grief, offer collegial empathy, and treat clinically toward grief work goals. Modeling an affirming response helps mitigate that which makes these losses disenfranchised.

For physician educators, preparing current doctorsin-training for an ever-evolving practice landscape might increase professional sustainability and physician satisfaction in the future. Indeed, investigators might examine whether mentorship schemes in postresidency settings reduce burnout.

For the physicians who have leadership roles in their practice or organization, there is much to do. It is essential and constructive that they bring an awareness of the extent to which organizational evolution causes shifts and losses that impact physicians' inner work life. Each organization will have to weigh the cost of ameliorating such unintended consequences. In the meantime, we must give the utmost respect and care to the consideration that physicians are potentially grieving, while upholding their professional role.

To read or post commentaries in response to this article, see it online at http://www.AnnFamMed.org/content/15/4/375.

Key words: burnout, professional; occupational medicine; occupational diseases; grief; cognitive dissonance; workplace; electronic health record; systems theory; disenfranchised grief; physician burnout; complicated grief

Submitted June 24, 2016; submitted, revised, December 6, 2016; accepted December 23, 2016.

Prior Presentations: Presented in part at Professional Longevity Beyond Resilience conference, Madison, Wisconsin, April 21, 2016.

Acknowledgments: The author thanks Dr Toby C. Campbell, MD of University of Wisconsin Hospitals and Clinics, and the Carbone Cancer Center, for his review of the manuscript, and mentorship; Christine A. Sinsky, MD, Mercy Medical Dubuque, Dubuque lowa, and Dr Helen Ullrich, PhD, MD, New Orleans, Louisiana for review of the manuscript.

\section{References}

1. Doka, K. Disenfranchised Grief: Recognizing Hidden Sorrow. New York, NY: Lexington Books; 1989.

2. Holmes TH, Rahe RH. "The social readjustment rating scale". J Psychosom Res. 1967;11(2): 213-218. http://www.emotionalcompetency. com/srrs.htm. Accessed Dec 2015.

3. Trudel L, Vonarx N, Simard C, et al. The adverse effects of psychological constraints at work: a participatory study to orient prevention to mitigate psychological distress. Work. 2009;34(3):345-357. 
4. Linzer M, Baier Manwell L, Mundt M, et al. Organizational climate, stress, and error in primary care: the MEMO study. In: Henriksen K, Battles JB, Marks ES, et al, eds. Advances in Patient Safety: From Research to Implementation (Vol 1: Research Findings). Rockville, MD: Agency for Healthcare Research and Quality; 2005:65-77.

5. Shanafelt TD, Boone S, Tan L, et al. Burnout and satisfaction with work-life balance among US physicians relative to the general US population. Arch Intern Med. 2012;172(18):1377-1385.

6. Peckham, C. Medscape physician lifestyle survey 2015. Medscape. http://www.medscape.com/features/slideshow/lifestyle/2015/public/ overview\#25. Published Jan 26, 2015. Accessed Sep 20, 2015.

7. Maslach C, Leiter MP. The Truth About Burnout: How Organizations Cause Personal Stress and What to Do About It. San Francisco, CA: Jossey-Bass; 1997.

8. Sinsky C, Colligan L, Li L, Prgomet M, Reynolds S, Goeders L, et al. Allocation of physician time in ambulatory practice: a time and motion study in 4 specialties. Ann Intern Med. 2016;165(11): 753760. http://annals.org/aim/article/2546704/allocation-physiciantime-ambulatory-practice-time-motion-study-4-specialties. Published Sep 6, 2016. Accessed Sep 7, 2016.

9. Stein AJ, Winokuer HR. Monday Mourning: Managing Employee Grief. In Doka K, ed. Disenfranchised Grief: Recognizing Hidden Sorrow. New York, NY: Lexington Books; 1989:94.

10. Romani M, Ashkar K. Burnout among physicians. Libyan J Med. 2014:9.

11. Shapiro SL, Astin JA, Bishop SR, Cordova M. Mindfulness-based stress reduction for health care professionals: results from a randomized trial. Int J Stress Manag. 2005;12(2):164-176.
12. Goodman MJ, Schorling JB. A mindfulness course decreases burnout and improves well-being among healthcare providers. Int J Psychiatry Med. 2012;43(2):119-128.

13. Krasner MS, Epstein RM, Beckman $\mathrm{H}$, et al. Association of an educational program in mindful communication with burnout, empathy, and attitudes among primary care physicians. JAMA. 2009;302(12):1284-1293.

14. Fortney L, Luchterhand C, Zakletskaia L, Zgierska A, Rakel D. Abbreviated mindfulness intervention for job satisfaction, quality of life, and compassion in primary care clinicians: a pilot study. Ann Fam Med. 2013;11(5):412-420.

15. Marine A, Ruotsalainen J, Serra C, Verbreed J. Preventing occupational stress in healthcare workers. Chochrane Database Syst Rev. 2006;8(4):CD002892. Review. Update in: Cochrane Database Syst Rev. 2014;11:CD002892.

16. Shanafelt TD, Gorringe G, Menaker R, et al. Impact of Organizational Leadership on physician Burnout and Satisfaction. Mayo Clin Proc. 2015;90(4):432-440.

17. Amabile TM, Kramer SJ. The Progress Principle: Using Small Wins to Ignite Joy, Engagement and Creativity at Work. Boston, MA: Harvard Business Review Press; 2011.

18. Dunn PM, Arnetz BB, Christensen JF, Homer L. Meeting the imperative to improve physician well-being: assessment of an innovative program. J Gen Intern Med. 2007;22(11):1544-1552.

19. Worden JW. Grief Counseling and Grief Therapy: A Handbook for the Mental Health Practitioner. 4th ed. New York, NY: Springer; 2009.

\section{CHANGE-OF-ADDRESS FORM EAMIIY MEDICDNE}

Please complete this form and mail to the following address or fax to Annals Circulation at 913-906-6080:

Annals of Family Medicine, Circulation Department, 11400 Tomahawk Creek Pkwy, Leawood, KS 66211-2680

Check if member of sponsoring organization:

$$
\begin{array}{ll}
\square \text { AAFP } \square \text { ABFM } \square \text { STFM } \square \text { ADFM } \\
\square \text { AFMRD } \square \text { NAPCRG } \square \text { CFPC }
\end{array}
$$

ID number from label on your journal cover

OLD Information (Please print.)

\begin{tabular}{ll}
\hline Name \\
\hline Company (if applicable) \\
\hline Address (Street plus Apt or Ste) & \\
\hline City & Postal Code (9-digit ZIP for US) \\
\hline Country & \\
\hline Telephone & \\
\hline E-Mail &
\end{tabular}

NEW Information (Please print.)

\begin{tabular}{ll}
\hline Name \\
\hline Company (if applicable) \\
\hline Address (Street plus Apt or Ste) & \\
\hline City & Postal Code (9-digit ZIP for US) \\
\hline Country & Fax \\
\hline Telephone & \\
\hline E-Mail
\end{tabular}

